\title{
Factors associated with hospitalization due to streptococcal infection in Houston, Texas 2015-2016
}

\author{
Razina Khayat*, Sudipa Biswas, Najmus Abdullah, Hafeez Rehman, Kirstin Short and \\ Salma Khuwaja
}

Epidemiology, City of Houston Public Health, Houston, TX, USA

\section{Objective}

To study the factors associated with streptococcal infection that led to hospitalization in Houston, Texas for years 2015-2016

\section{Introduction}

Different studies have shown that Streptococcal infections in adults are more common among older age, blacks, and underlying chronic medical conditions like diabetes, cardiovascular and kidney diseases.

In specific, other studies have demonstrated that streptococcal pyogenes can cause severe illnesses and dramatic hospital outbreaks.

Furthermore, community-acquired pneumonia studies had also suggested that cardiovascular disease, severe renal disease, chronic lung disease and diabetes were associated with increased odds of hospitalization.

\section{Methods}

Data were extracted from Houston Electronic Disease Surveillance System (HEDSS) beginning January 1, 2015 to December 31, 2016. A total of 512 confirmed cases were investigated and analyzed during the study period. Frequencies and percentages were calculated and chi square test was used to examine the association between hospitalization and other risk factors. Odds ratio was calculated using unconditional logistic regression to determine the association of risk factors with hospitalization in streptococcal patients.

\section{Results}

A total of 414 patients $(81 \%)$ of the confirmed cases were hospitalized.

Age, race, fever, sepsis, diabetes, cardiovascular and kidney diseases were significantly associated with hospitalization in the bivariate analysis.

Logistic regression analysis adjusted for confounding factors demonstrated that among clinical characteristics, fever (OR 2.9; 95\% CI 1.66-5.38) was three times more prevalent among hospitalized patients with streptococcal infection.

Patients with diabetes (OR 7.92; 95\% CI 3.08-20.36) were almost eight times more likely to be hospitalized than patients without diabetes among streptococcal patients, followed by cardiovascular disease (OR 2.84; CI 1.32-6.10) which was three times more likely to be present.

\section{Conclusions}

Common clinical sign like fever was associated with hospitalization among streptococcal patient. Similarly, risk factors like diabetes and cardiovascular diseases were significantly associated with hospitalization in streptococcal patients.

Prevention strategies need to be focused on streptococcal patients with chronic risk factors like diabetes, and cardiovascular disease.

\section{Keywords}

Streptococcal infection; Hospitalization; Chronic Diseases

\section{Acknowledgments}

Thanks to the City of Houston Health Department

\section{References}

Parks t, Barret L, Jones N. Invasive streptococcal disease: a review for clinicians. British Med Bulletin, 2015; 115 (7): 77-89.

Skoff TH, Farley MM, Petit S, et al. Increasing Burden of Invasive Group B Streptococcal Disease in Nonpregnant Adults, 1990-2007. CID 2009; 49 (7): 85-92.

\section{*Razina Khayat}

E-mail: razina.khayat@houstontx.gov 